Черкесова Лариса Ивановна

Кандидат юридических наук

Ведущий научный сотрудник

Институт государства и права РАН

\title{
ЗАКОНОДАТЕЛЬСТВОРОССИИ ОБ ЭЛЕКТРОЭНЕРГЕТИКЕ В КОНТЕКСТЕ ИНТЕГРАЦИОННЫХ ПРОЦЕССОВ ЕАЭС
}

Аннотация: Энергетическое сотрудничество государств - членов Евразийского экономического союза (далее - Союз, ЕАЭС и члены ЕАЭС) играет важнейшую роль в рамках евразийской экономической интеграции. Члены ЕАЭС ставят своей целью создание общих энергетических рынков Союза. При этом наиболее интенсивно развивается интеграция электроэнергетики.

В статье анализируются энергетические положения Договора о Евразийском экономическом союзе, выявляется роль национального законодательства и двусторонних международных договоров членов ЕАЭС в сфере электроэнергетики. Дается краткий анализ динамики развития законодательства Российской Федерации в сфере электроэнергетики и определяются перспективы его развития на фоне развития электроэнергетической интеграции ЕАЭС. Высказаны отдельные предложения по повышению эффективности интеграционных процессов ЕАЭС в сфере электроэнергетики и гармонизации законодательства.

Данная статья не претендует на роль детального научного исследования вопроса трансформации законодательства об электроэнергетике России, а является попыткой обозначить, во-первых - один из наиболее весомых на сегодняшний день фактор влияния и, во-вторых - назревшую необходимость дальнейшего изучения данного вопроса.

Ключевые слова: интеграционные прочессы, Евразийский экономический союз, энергетическая интегращия, электроэнергетика, законодательство об электроэнергетике, общий электроэнергетический рынок ЕАЭС, гармонизаџия законодательства. 
Keywords.: integration processes, Eurasian Economic Union, energy integration, electricity, electricity legislation, the common electricity market of the EAEU, harmonization of legislation.

Неизбежность интеграционных процессов во всем мире подтверждена временем. При этом совершенно очевидно, что консолидация государств по экономическим критериям трансформирует политическую, технологическую и правовую конструкции во всех отраслях экономики. В этой связи совершенно очевидно, что возникла необходимость применения научных подходов к исследованию роли интеграционных процессов в преобразовании законодательства России, поскольку только фундаментальная и по-настоящему академическая государствоведческая и правоведческая теория, использующая весь арсенал методологических средств, отрешенная от идеологизации, может стать не только закономерным следствием и созидательным условием позитивного развития политико-правового процесса, а выступить факторам единения и согласия общества, переживающего кризис.

Проведение подобных научных исследований в настоящий момент также весьма важно с учетом новых мировых вызовов. В частности:

создание Китаем, Австралией, Японией и еще 12 странами АзиатскоТихоокеанского региона крупнейшей в мире зоны свободной торговли - «Всестороннего регионального экономического партнерства» (ВРЭП). Соответствующий документ был подписан 12 ноября 2020 года по итогам саммита стран Ассоциации государств ЮгоВосточной Азии (АСЕАН) в столице Вьетнама Ханое.

прозвучавшее на 75-й сессии Генассамблеи ООН предложение Президента России В.В. Путина создать глобальный интеграционный экономический проект, включающий все страны Европы и Азии - Большое евразийское партнерство, в целях усиления международной кооперации для преодоления социально-экономических последствий пандемии коронавирусной инфекции- как в рамках ООН, так и в формате «большой двадцатки», а также прочих интеграционных объединений, так как «восстанавливать глобальную экономику предстоит... очень долго».

Учитывая, что электроэнергетика является стратегически важной отраслью, влияющей на функционирование практически всех направлений экономики, от степениразвития которой зависит социально-политический и финансово-экономический уровень государства, изучение тенденций развития законодательства России в сфере 
электроэнергетики, в том числе под влиянием интеграционных процессов представляется крайне актуальным.

Для современного законодательства Российской Федерации в сфере электроэнергетики характерно динамичное развитие, обусловленное происходящими изменениями, связанными с быстрым темпом социально-экономических преобразований в стране и мире, процессами мировой глобализации и региональной интеграции, а также переходом к обществу информационных технологий и сменой ценностных ориентаций.

Начало большого пути процесса эволюции государственно-правового регулирования на законодательном уровне правоотношений в сфере электроэнергетики было положено на фоне интенсивно развивающихся процессов формирования рыночной экономики - немногим больше 20 лет назад. Старт процессам реформирования отрасли был дан Правительством Российской Федерации в июле 2001 года, посредством определения основных направлений реформирования электроэнергетики Российской Федерации [1], предусматривающих проведение реформы в три этапа за 8-11 лет.

Именно в этот период были приняты основополагающие законодательные акты в данной сфере регулирования. В частности, Федеральные законы от 26.03.2003 № 35-Ф3 «Об

электроэнергетике»

(далее - Закон об электроэнергетике) [2], от 23.11.2009 № 261-Ф3 «Об энергосбережении и о повышении энергетической эффективности и о внесении изменений в отдельные законодательные акты Российской Федерации» [3], от 21.11.1995 № 170-Ф3 «Об использовании атомной энергии» [4], от 17.08.1995 № 147-Ф3 «О естественных монополиях» [5].

Особо значимым событием данного процесса было принятие Закона об электроэнергетике, который обозначил комплексный подход к правовому регулированию данных правоотношений. По существу Закон об электроэнергетике является кодифицированным актом, юридически закрепляющим правила поведения в сфере электроэнергетики.

Законом об электроэнергетике легитимирована Единая энергетическая система России, установлены принципы и механизмы организации и функционирования электроэнергетической отрасли, закреплена ее структура, субъектно-объектный состав и условия деятельности, а также регламентированы гражданско-правовые отношения. И что весьма важно - наличие обширного понятийного аппарата, которым законодательно закреплены определения понятий, используемых в электроэнергетике. Кроме того, в 
законе содержится перечень методов государственного регулирования и контроля в сфере электроэнергетики.

В развитие Закона об электроэнергетике принят обширный массив подзаконных нормативных правовых актов, в большинстве своем представленных постановлениями Правительства Российской Федерации и, по сути, правовое обеспечение реформирования электроэнергетической отрасли было завершено. Законодательство об электроэнергетике, удовлетворяющее на тот момент потребностям государства и общества, сформировано.

Однако складывающаяся все последующие годы правоприменительная и судебная практика выявляли отдельные недостатки в регламентации данных правоотношений: неоднозначность толкования, пробелы правового регулирования, внутренние противоречия, а в отдельных случаях и несоответствие Конституции Российской Федерации [6; 7]. Кроме того, экономические факторы воздействия (мировые экономические вызовы, интеграционные процессы, развитие инфраструктуры, технологий, возникающие риски и иное) требовали адекватного реагирования и соответствующей адаптации законодательства.

Вышеуказанными обстоятельствами обусловлены значительные изменения законодательства в сфере электроэнергетики за прошедший период времени. В частности, за 17 прошедших лет в Закон об электроэнергетике были внесены изменения 60-ю федеральными законами. Большинство из них точечного характера, но были и достаточно существенные - в 2007 и 2010 годах [8; 9]. В итоге на сегодняшний день подавляющее большинство норм Закона об электроэнергетике изложены иначе, чем в первоначальной редакции.

Как видим, законодательство России в сфере электроэнергетики динамично развивается. В тоже время, учитывая, что электроэнергетика является стратегически важной для страны сферой экономической деятельности, хаотичное еe развитие недопустимо. И как следствие можно наблюдать развитие процессов стратегического планирования, формирующих модели развития отрасли, системно определяющих основные цели, задачи, приоритеты и направления, а также механизмы реализации. При этом основополагающими программными документами, учитывающими переход России к новой модели социально-экономического развития [10], являются Доктрина энергетической безопасности Российской Федерации [11] и Энергетическая стратегия Российской Федерации на период до 2035 года [12], предусматривающие комплекс мероприятий по ускоренному переходу энергетического сектора на более высокий 
качественный уровень (высокоэффективной, гибкой и устойчивой энергетике), реализация которых приведет к широкомасштабным изменениям - диверсификации энергетического сектора и переходу на более эффективную модель государственного управления (переформатированию, как архитектуры, так и принципов государственного управления), что повлечет за собой значительные, можно даже сказать кардинальные, изменения нормативного регулирования правоотношений в сфере электроэнергетики.

Одновременно с этим, исследуя вопросы формирования электроэнергетического законодательства России, недопустимо отстранятся от происходящих мировых интеграционных процессов, которые в большей либо в меньшей мере затрагивают и вопросы трансформации Российского электроэнергетического законодательства.

На фоне всеобщей глобализации, динамично развивающиеся во всем мире экономические интеграционные процессы, являющие собой новый уровень консолидации государств, это тренд современной эпохи.

Формирование интеграционных объединений осуществляется как по региональным, так и по отраслевым признакам.

Наиболее востребованными с точки зрения эффективности решения основополагающих социально-экономических задач на сегодняшний день являются региональные интеграционные объединения, которых в мире насчитывается порядка двадцати.

Правовой основой экономической консолидации государств являются межгосударственные соглашения (договоры), содержащие нормативные предписания, касающиеся интеграции различных сфер экономической деятельности, и соответственно при их внедрении в правовых системах стран-участниц также наблюдаются интеграционные процессы. При этом обращает на себя внимание тот факт, что межгосударственные экономические интеграционные соглашения, как правило, декларируют гармонизацию законодательства сторон с последующей ее унификацией.

Таким образом, можно говорить о том, что мировые интеграционные процессы являются одним из факторов, порождающих трансформацию законодательства, как в Российской Федерации, так и в иных странах мира.

Законодательство об электроэнергетике тоже не исключение. Рассмотрим перспективы его изменения в контексте интеграционных процессов ЕАЭС, являющихся доминирующими для России, учитывая историческую общность народов постсоветского пространства, а также сохранившиеся экономические и технологические связи. 
Не будем останавливаться на анализе энергетического влияния данного регионального интеграционного объединения в период прохождения им этапов эволюции и становления, поскольку, на наш взгляд, его функционирование именно в рамках Договора о Евразийском экономическом союзе от 29 мая 2014 года [13] (далее - Договор ЕАЭС), закрепившего понятие права ЕАЭС и наиболее детально сформировавшего нормативную позицию по сближению в энергетической сфере, при благоприятном развитии событий может существенно отразиться на энергетическом законодательстве России.

Положения, касающиеся энергетики, содержаться в части третьей Договора ЕАЭС, регламентирующей формирование единого экономического пространства. Энергетике посвящен раздел $\mathrm{XX}$, в котором особое внимание, учитывая общую электроэнергетическую инфраструктуру постсоветского пространства и сложившееся еще в советские времена взаимодействие [14, с. 7], традиционно уделено электроэнергетике, как наиболее перспективному для сближения сегменту энергетической сферы экономической деятельности. Чрезвычайно важным является тот факт, что Договором ЕАЭС, декларирующим скоординированную энергетическую политику (наименьшая степень сближения) и взаимовыгодное сотрудничество (что, как мы понимаем, является достаточно обобщенными понятиями), зафиксировано решение о поэтапном формировании общих рынков энергоресурсов [15, с. 47-48] а также гармонизация технологических и коммерческих правил функционирования инфраструктуры энергетики (также звучит не вполне конкретно и может предполагать практически полное правовое регулирование).

Вопросам электроэнергетики, как уже говорилось выше, в Договоре ЕАЭС уделено достаточно большое внимание. Помимо общих положений о взаимодействии и сотрудничестве в сфере энергетики, содержащихся в статье 79 Договора ЕАЭС, и общих принципов и правил раздела XIX (естественные монополии), вопросы электроэнергетики подробно регулируются статьями 81, 82 и 104 Договора ЕАЭС о формировании общего рынка электроэнергетики иобеспечении доступа к услугам естественных монополий в указанной сфере.

Кроме того, правоотношениям в области электроэнергетики посвящены приложения 1 и 21 Договора ЕАЭС, определяющие сферы естественных монополий в электроэнергетике, где подробно регламентируются правила доступа к ним, а также основы ценообразования и тарифной политики. 
Причем основная стратегическая цель, целевой ориентир энергетической интеграции в рамках ЕАЭС в сфере электроэнергетики - это создание экономически эффективного общего рынка (но не единого - как это предполагалось изначально) электроэнергии ЕАЭС, объединенного общими политическими, экономическими, организационными и нормативно-технологическими принципами и правилами функционирования и взаимодействия. При этом общий рынок электроэнергии, согласно статье 81 Договора ЕАЭС, это комплекс экономических отношений хозяйствующих субъектов по вопросам купли-продажи электроэнергии (мощности), базирующийся на параллельно действующих национальных энергетических системах государств-членов, регламентируемый энергетическим законодательством ЕАЭС [16, с. 147-148].

Договором ЕАЭС определены организационно-технологические (порядок подачи заявок, определения технологических возможностей, планирование и др.), экономические (в том числе, ценообразование и тарифное регулирование) и правовые (например, требования к договорам) критерии формирования общего рынка электроэнергии, его структура, можно сказать - модель региональной электроэнергетической интеграции [17, c. 222], внедрение которой потребует трансформации принципов работы национальных систем электроэнергетики стран-участниц, и как следствие - изменение национального законодательства в сфере электроэнергетики.

В то же время обращает на себя внимание тот факт, что Договор ЕАЭС, в части, касающейся как электроэнергетики, так и энергетики в целом, содержит значительное количество отсылок к национальному законодательству государств-членов, что свидетельствует о пока еще существующей высокой степени зависимости нормативноправового регулирования функционирования электроэнергетики ЕАЭС (энергетического права ЕАЭС) от энергетического законодательства стран-участниц ЕАЭС [18, с. 32].

В целях реализации положений Договора ЕАЭС по формированию общего рынка электроэнергии и во исполнение пункта 2 статьи 81 Договора ЕАЭС в мае 2015 года утверждена Концепции формирования общего электроэнергетического рынка Евразийского экономического союза (далее - Концепция) [19], а в декабре 2016 года Программа формирования общего электроэнергетического рынка Евразийского экономического союза (далее - Программа) [20].

Концепция является комплексным нормативным правовым документом ЕАЭС, устанавливающим правила игры на переходный период - период формирования общего рынка электроэнергии, в котором определены: цели, задачи, принципы и этапы 
формирования общего рынка электроэнергии (разделы II-IV, XIII Концепции); функциональная, управленческая и субъектно-объектная структура (разделы V-VIII Концепции); механизмы ценообразования (разделIX Концепции); система нормативных регуляторов общего рынка электроэнергии (Раздел XII Концепции).

На основе анализа положений Концепции можно выделить следующие основные признаки формируемого ею общего рынка электроэнергии ЕАЭС:

- общий рынок электроэнергии ЕАЭС функционирует на основе параллельно действующих систем электроэнергетики государств-членов;

- субъектами общего рынка электроэнергии ЕАЭС являются: организации участники оптовых рынков электроэнергии государств-членов, осуществляющие куплюпродажу электрической энергии; инфраструктурные организации (системные, сетевые и финансовые операторы и операторы централизованных торгов);

- взаимная торговля электроэнергией осуществляется: на договорной основе по соглашению сторон (свободный двухсторонний договор) и на централизованных торгах (излишки);

- ценообразование на общем рынке электроэнергии ЕАЭС формируется с учетом механизмов ценообразования государств-членов на рыночной основе;

- цены (тарифы) на электроэнергию при заключении свободных двухсторонних договоров определяются по соглашению сторон;

- цены (тарифы) на услуги субъектов естественных монополий (инфраструктурных организаций) определяются в соответствии с законодательством государств-членов, но не выше внутригосударственных;

- доступ к услугам естественных монополий свободный, с учетом приоритета внутренних потребностей государств-членов.

Таким образом, можно сделать вывод о том, что модель общего рынка электроэнергии ЕАЭС в формате Концепции обладает минимальной регулятивной составляющей и в своей основе базируется на уже существующем в государствах-членах ЕАЭС нормативно-правовом регулировании функционирования сферы электроэнергетики, а имплементация правовых основ данной модели общего рынка в электроэнергетическое законодательство России на сегодняшний день затронет, пожалуй, только нормативно-правовое регулирование вопросов недискриминационного доступа к услугам естественных монополий и организации торгов. В этой связи представляется 
обоснованной позиция отдельных исследователей данной проблематики о том, что такого рода модель общего рынка электроэнергии не требует унификации законодательства государств-членов, а предполагает гармонизацию [17, с. 223].

Программа формирования общего электроэнергетического рынка Евразийского экономического союза, принятая в 2016 году, по существу более детально раскрывает положения Концепции, а также формирует дорожную карту создания общего рынка электроэнергии ЕАЭС (план мероприятий по формированию общего электроэнергетического рынка ЕАЭС). И что является наиболее значимым с правовой точки зрения - это наличие специального раздела, определяющего перечень нормативноправовых актов ЕАЭС, составляющих систему актов, регламентирующих правоотношения, касающиеся общего рынка электроэнергии (раздел VIII Программы), к которым отнесены:

- международный договор о формировании общего электроэнергетического рынка Союза, содержащий, в том числе, единые правила доступа к услугам субъектов естественных монополий в сфере электроэнергетики;

- свод правил общего электроэнергетического рынка Союза, включающий в том числе: правила взаимной торговли электрической энергией; правила определения и распределения пропускной способности;положение о развитии межгосударственных электрических сетей;правила информационного обмена;иные акты, регулирующие общий электроэнергетический рынок Союза.

Однако вызывает серьезную озабоченность отсутствие в таких стратегически важных для развития интеграции электроэнергетики документах, как Договор ЕАЭС (в части электроэнергетики), Концепция и Программа формирования общего рынка электроэнергии ЕАЭС, научно-технической составляющей (совместные научные исследования и разработки в области электроэнергетики), что, безусловно, может негативно сказаться на возможностях выхода сферы электроэнергетики на более высокий, инновационный путь развития [21;22, с. 40-41].

При этом следует учитывать, что рассматриваемая модель общего рынка электроэнергии ЕАЭС - это промежуточный вариант. В перспективе, по итогам реализации намеченных мероприятий по созданию общего рынка электроэнергии ЕАЭС предполагается углубление интеграционных процессов в сфере электроэнергетики, а при благоприятном развитии событий возможен возврат к идее формирования не общего, а единого рынка электроэнергии ЕАЭС, что, соответственно, потребует уже не 
гармонизации, а унификации законодательства государств-членов и, совершенно очевидно, приведет к существенным изменениям законодательства в сфере электроэнергетики России.

В заключении хотелось бы отметить следующее.

Учитывая стратегическое значение электроэнергетики, одним из основополагающих факторов эффективного развития Евразийского экономического союза можно считать интеграционные процессы в сфере электроэнергетики и создание единого рынка электрической энергии ЕАЭС.

В настоящее время электроэнергетическая интеграция находится в начальной стадии своего развития, поскольку провозглашенная Договором ЕАЭС скоординированная политика в сфере электроэнергетики и создание общего рынка электроэнергии - это минимальный уровень сближения.

Учитывая различную степень развития электроэнергетики государств-членов ЕАЭС, а также приоритет национальных интересов, можно говорить о том, что уровень и интенсивность процессов электроэнергетической интеграции находится в прямой зависимости от эффективного взаимодействия органов государственной власти государств-членов и доброй воли компромиссов на взаимовыгодной основе.

Важным фактором является нормативно закрепленная система актов, регламентирующих правоотношения, касающиеся общего рынка электроэнергии, которые в совокупности с положениями об электроэнергетике Договора ЕАЭС, по существу можно квалифицировать как законодательство ЕАЭС об электроэнергетике.

Развитие и эффективность энергетического права ЕАЭС находится в прямой зависимости от политической воли членов ЕАЭС, степени их реальной заинтересованности в укреплении энергетического сотрудничества в рамках ЕАЭС и добросовестной реализации принятых программ ЕАЭС на практике.

Наличие самостоятельного нормативно-правового регулирования отдельных правоотношений в сфере электроэнергетики в рамках ЕАЭС во взаимосвязи с основным принципом формирования общего электроэнергетического рынка ЕАЭС - гармонизация законодательства об электроэнергетике - является фактором влияния на развитие и трансформацию законодательства России в сфере электроэнергетики.

На данном этапе развития электроэнергетической интеграции влияние интеграционных процессов на законодательство России в сфере электроэнергетики будет 
минимальным. Дальнейшее углубление интеграционных процессов может привести полному единению электроэнергетических рынков государств-членов ЕАЭС и, соответственно, усилит степень влияния на национальное энергетическое законодательство, будет способствовать существенной его трансформации.

Необходимо также рассмотреть вопрос о включении в интеграционные процессы электоэнергетической составляющей такого весьма значимого сегмента как атомная энергетика, в развитии которого Российская Федерация занимает ключевую позицию на мировой арене [23, с. 124].

Учитывая стратегически важное значение евразийской интеграции, и дальнейшее динамичное развитие консолидации государств-членов ЕАЭС в сфере электроэнергетики, представляется необходимым осуществлять мониторинг правоприменения законодательства ЕАЭС об электроэнергетике и постоянно совершенствовать правовое регулирование, устраняя недостатки и пробелы. При этом полагаем весьма важно в данной работе учитывать мнение не только бизнес, но и научного сообщества. При этом ключевым фактором успешного функционирования и развития интеграционных процессов ЕАЭС в электроэнергетике является гармонизация законодательства государств-членов ЕАЭС, с последующей его унификацией.

\section{Литература:}

1. Постановление Правительства РФ от 11.07.2001. № 526 «О реформировании электроэнергетики Российской Федерации» // СЗ РФ 2001. № 29. ст. 3032.

2. Федеральный закон от 26.03.2003. № 35-Ф3 «Об электроэнергетике» // С3 РФ 2003. № 13, ст. 1177.

3. Федеральный законот23.11.2009 №261-Ф3 «Об энергосбережении и о повышении энергетической эффективности и о внесении изменений в отдельные законодательные акты Российской Федерации» // С3 РФ 2009. № 48, ст. 5711.

4. Федеральный закон от 21.11.1995 N 170-Ф3 «Об использовании атомной энергии» // СЗ РФ 1995. № 48, ст. 4552.

5. Федеральный законот17.08.1995 № 147-ФЗ«Оестественных монополиях» // С3 РФ 1995. № 34, ст. 3426.

6. Постановление Конституционного Суда РФ от 25.04.2019 № 19-П «По делу о проверке конституционности пункта 6 Правил недискриминационного доступа к 
услугам по передаче электрической энергии и оказания этих услуг в связи с жалобой акционерного общества "Верхневолгоэлектромонтаж-НН"» / СЗ РФ 2019. № 18, ст. 2268.

7. Постановление Конституционного Суда РФ от 20.12.2018 № 46-П «По делу о проверке конституционности абзаца второго пункта 40 Правил предоставления коммунальных услуг собственникам и пользователям помещений в многоквартирных домах и жилых домов в связи с жалобами граждан В.И. Леоновой и Н.Я. Тимофеева» / С3 РФ 2018. № 53 (часть II), ст. 8795.

8. Федеральный закон от 04.11.2007 № 250-Ф3

9. Федеральный закон от 26.07.2010 № 187-Ф3.

10. Доктрина энергетической безопасности Российской Федерации (п. 15 Раздел II) // Указ Президента РФ от 13.05.2019 № 216 "Об утверждении Доктрины энергетической безопасности Российской Федерации" // СЗ РФ 2019, № 20, ст. 2421.

11. Указ Президента РФ от 13.05.2019 № 216 "Об утверждении Доктрины энергетической безопасности Российской Федерации" // С3 РФ 2019, № 20, ст. 2421.

12. Распоряжение Правительства РФ от 09.06.2020 № 1523-р «Об утверждении Энергетической стратегии Российской Федерации на период до 2035 года» / С3 РФ 2020. № 24 , ст. 3847.

13. Договор о Евразийском экономическом союзе от 29 мая 2014 г. // Официальный сайт Евразийской экономической комиссии

http://www.eurasiancommission.org/, 05.06.2014 и Официальный интернет-портал правовой информации http://www.pravo.gov.ru, 16.01.2015.

14. Громов А.И. Евразийский энергетический союз: Реальность и перспективы. // Энергетическая политика. 2011. № 6. С. 3-9.

15. Борисова Ю.М. Будущий общий рынок электроэнергии в странах ЕАЭС: проблемы и перспективы. Проблемы постсоветского пространства. 2019;6(1) С. 43- 52.

16. Солодухина О.И., Харланова В.Н., Буданцева Ю.И. Институциональные основы формирования общего электроэнергетического рынка Евразийского экономического союза. // Вестник Алтайской академии экономики и права. 2019. № 2-1. С. 146-151.

17. Мигранян А.А., Шавина Е.В. Формирование общих рынков электроэнергии и газа в ЕАЭС: модели рынков, барьеры и решения // Контуры глобальных трансформаций: политика, экономика, право. Т. 12. № 6. 2019. С.220-245. 

18. Гликман
O.B.,
Назарова
A.У.
Международно-правовые основыэнергетического сотрудничества государств-членов Евразийского экономического союза // Право и управление. XXI век. 2020. Т. 16. № 1 (54). С. 28-35.

19. Решение Высшего Евразийского экономического совета от 08.05.2015 № 12 «О Концепции формирования общего электроэнергетического рынка Евразийского экономического союза» // Официальный сайт Евразийского экономического союза http://www.eaeunion.org/, 12.05.2015.

20. Решение Высшего Евразийского экономического совета от 26.12.2016 № 20 «О Программе формирования общего электроэнергетического рынка Евразийского экономического союза» // там же, 11.04.2017.

21. Цедрик А.В. Общий энергетический рынок стран ЕАЭС: Анализ, риски и барьеры на пути к интеграции, рекомендации // Материалы II Международной научной конференции «Тенденции экономического развития в ХХІ веке», ред. Королева А.А. 2020, Белорусский государственный университет, Минск.

22. Евразийская экономическая интеграция: перспективы развития и стратегические задачи для России. Доклад НИУ ВШЭ на ХХ апрельской международной экономической конференции по проблемам развития экономики и общества (9-12 апреля 2019 г.) // НИУ ВШЭ России, Всемирный банк - Издательский дом НИУ ВШЭ, М. 2019, $123 \mathrm{C}$.

23. Шпинев Ю.С. Правовое регулирование инвестиций в атомную энергетику // Инновации. Наука. Образование. 2020. № 17. C. 124-134. DOI 10.18411/1311-1972-202000013. 